\title{
ON SEA LEVEL ALONG THE BRAZILIAN COAST
}

\author{
Afrânio Rubens de Mesquita, Alberto dos Santos Franco, \\ Joseph Harari and Carlos Augusto de Sampaio França
}

\begin{abstract}
This is Part II of a contribution on Brazilian sea levels - Part I dealt with the seasonal variability. It examines the sea level changes along the Brazilian coast from series with less than 40 years of measurement, against the background of changes in series of all continents and islands around the world, considering data distributed by the Permanent Service for Mean Sea Level (PSMSL). The method of analysis follows the display of the data in a: 1) first plot of relative sea level trends $(C)$, against the length of the series $(L)$ expressed in years and a: 2) second plot showing the relative sea level regression coefficients $(C)$, versus the corresponding correlation values (m). The first plot of all PSMSL data exhibited a cusped like shape of the distribution of (C), having maxima values about $10-20 \mathrm{~cm} / \mathrm{cty}$ for the longest series (120-137 years), indicating the overall positive value of the global relative sea level trend. Similar first plot, a regional plot of African and South American data adjusted to the same global relative mean level, showed that the Brazilian trends (C), are mostly concentrated in the positive side of the cusped: (ports of Belém, Fortaleza. Recife, Canavieiras, Salvador, Ilha Fiscal, Rio de Janeiro, Ubatuba, Cananeia, and Imbituba) which have a mean value within 30 to $40 \mathrm{~cm} / \mathrm{cty}$. The second plot, with all set of PSMSL data, was necessary in order to display trend values of non simultaneous series of different continental borders and lengths in the same bin. The plot gave two different linear inclinations for trend values within $\pm 0.3 \mathrm{~cm} / \mathrm{y}$, in the positive and negative sides of the figure. The global ratio obtained for the trends was $R=-1.2$, suggesting also, from the linearity of the plot, that the trends and correlation values are statistically dependent variables. The graph produced a different value for global balance of the value $\mathrm{C}$ obtained in the first plot. Similar regional second plot of the African Atlantic and South American borders, which include the Brazilian data, also gave rise to two new regression lines with trend $C^{*} 1<0$ and $C * 2>0$, with a ratio $R=-2.2$, involving bins of $m$ and $C$ values that are also null in the vicinity of zero. This regionally plot confirmed the result of the second plot with PSMSL series that they $(\mathrm{C}$ and $\mathrm{m})$, globally, should be dependent statistical variables. These findings, however, do not change the fact that the regional series with trends $0.2 \mathrm{~cm} / \mathrm{year}$ have correlation values $\mathrm{m}<0.3$, whatever their lengths, and that the mean value of the relative sea level, along the Brazilian coast, is increasing with an estimated rate of 30 to $40 \mathrm{~cm} / \mathrm{cty}$. Further work is under way, aiming at solving the above apparently contradictory results.
\end{abstract}

Keywords: sea level, Brazilian coast, PSMSL series, global relative sea level, imbalance of relative sea level.

RESUMO. Esta é a segunda parte de uma contribuição sobre os níveis do mar na costa brasileira - a parte I tratou da variação sazonal - ela examina as mudanças do nível do mar ao longo da costa brasileira a partir de séries com comprimentos menores do que 40 anos contra as variações das séries de todas as ilhas e continentes do globo, levando em conta as séries distribuídas pelo Permanent Service for the Mean Sea Level (PSMSL). A descrição é feita através da exposição dos dados em 1) um gráfico das tendências $(C)$ contra o comprimento das séries $(L)$ em dados anuais e um 2) segundo gráfico mostrando as tendências dos níveis relativos (C) contra os valores dos valores das correlações (m) entre as séries e os dados da sua reta de regressão. 0 primeiro gráfico com as séries do PSMSL mostrou uma forma de cúspide como distribuição de (C) com valores máximos de cerca de 10-20 cm/século para as séries mais compridas (120-137 anos). Figura semelhante com dados da América do Sul e da África ajustada para essa média, mostra o mesmo padrão (portos de Belém, Fortaleza, Canavieiras, Salvador, Ilha Fiscal, Rio de Janeiro, Ubatuba, Cananeia e Imbituba). 0 segundo gráfico foi necessário para a análise de séries com comprimentos diversos e não simultâneas como as séries do PSMSL, produziu duas novas retas com inclinações $C^{*} 1<0$ e $C^{*}>0$ construídas a partir dos valores das tendências $C$ das séries PSMSL, com inclinações dentro da faixa de $0,2 \mathrm{~cm} /$ ano na parte positiva e negativa da figura, sugerindo uma não equivalência entre essas inclinações, em favor de valor global negativo de $C^{*}$ para 0 Nível Relativo do Mar. Figura semelhante produzida com as séries Africanas e Sul Americanas, que incluíram as séries brasileiras, mostrou característica similar, além de indicar que séries com tendências $\pm 0,2 \mathrm{~cm} /$ ano têm valores de correlação $\mathrm{m}<0,3$ qualquer que seja 0 comprimento da série. Os resultados interessantes, mas contraditórios, que incluem a dependência linear global entre correlação e tendências das séries fornecidas pelo PSMSL, devem ser analisados em continuação aos presentes estudos, que indicam que o nível relativo do mar na costa brasileira está aumentando à razão de 30 a $40 \mathrm{~cm} /$ século.

Palavras-chave: nível do mar, costa brasileira, séries do PSMSL, nível relativo do mar global, balanço do nível relativo do mar.

Departamento de Oceanografia Física, Instituto Oceanográfico-USP, Praça do Oceanográfico, 191, 05508-900 Cidade Universitária, São Paulo, Brazil. Phones: +55(11) 3091-6648 / 3091-6584 - E-mails: ardmesqu@usp.br; asfranco@intercall.com.br; joharari@usp.br; cafranca@usp.br 


\section{INTRODUCTION}

Current trends of global and regional sea level have been estimated by several authors (Gornitz et al., 1982; Barnett, 1983; Woodworth, 1990). Concern is expressed by several scientists that global sea levels may be rising significantly as a result of the greenhouse effect. The sea level rising has a huge impact on the public opinion and scientific journals. Trends of the sea level variation differ on magnitude and time-scale from one geographical area to another and different overall values have been obtained by each author (Gornitz et al., op. cit.; Barnett, op. cit.). This aspect is appreciated along this study in Part II.

Part I of this paper dealt with the seasonal variation (Mesquita et al., 1986). Part II examines the long term sea level changes along the Brazilian coast within the background of the corresponding changes along the continents and island taken from worldwide data distributed by the Permanent Service for the Mean Sea Level (PSMSL).

The description follows the display of the data in simple figures; one is a plot of sea level trends against the lengths of the series; the other is a display of the sea level trends against the correlation of data and their predictions given by the regression lines. The first figure allows us to inspect the Brazilian trends and all the world's distribution of trends and the lengths of the series, The second figure allows us to split the negative and positive values of the trends and to speculate how these values compare, on a global scale, giving rise to inferences between the correlations and trends of each continent and coastal lines.

Attention in this paper is focused mostly, on the Brazilian data, they are, however, from relatively short records compared to most of the world's measurements, which form the basic background they have to conform with.

\section{MATERIAL AND METHODS}

The data used in this work are the annual mean of relative sea level values distributed by the Permanent Service for the Mean Sea Level (PSMSL). The Brazilian data are from the ports of Salinópolis, Belém, Fortaleza, Recife, Salvador, Canavieiras, Itha Fiscal, Rio de Janeiro, Ubatuba, Cananeia and Imbituba, covering almost all the coast from North to the South (Fig. 1).

These series are relatively short compared to the world's sea level series. Most of them starting by the year of 1947 and ending by the year of 1967. Exceptions are the series of the Belém, Recife, from the Instituto Nacional de Pesquisas Hidroviária, (INPH), Ilha Fiscal, maintained by the Diretoria de Hidrografia e Navegação (DHN), Ubatuba and Cananeia, maintained by the Instituto Oceanográfico of the Universidade de São Paulo (Fig. 2).
The number of years length $(\mathrm{L})$, the long term trends of the sea level $(C)$, and the values of correlation $(m)$ of each series were calculated for stations of the African and South American Atlantic coasts. Most of the measurements are non simultaneous and there are also different gaps in each series. For this reason it is difficult to calculate a sort of average trend for the listed ports. In order to look at the data globally, a plot of all trends, including those from series with less than 15 years, was produced. This was necessary because most of the Brazilian series in this study have less than 30 years of measurements.

\section{The first plot for analysis: trends C of all PSMSL series}

In Figure 3 are shown the trend values $(C)$ of all ports listed by the PSMSL as RLRANN data, i.e., data which are followed by yearly (or less) repeated reference to a national datum as a level reference, against the length $(L)$ of the series, including the ones from the South American and Atlantic African ports. Black dots indicate the $(C)$ values for Brazilian ports, which show positive and negative trends having most of values lying in the positive side of the figure. It is difficult to give a value for the mean regional values of the Brazilian trends, but a rough estimate of $20-30 \mathrm{~cm} / \mathrm{cty}$ is obtained from the ports shown as dots in the figure.

An estimate of the mean global value for the area of interest from PSMSL data is also difficult to produce, as the trend values are well distributed from the extreme values (positive and negative) from $+4 \mathrm{~m} / \mathrm{cty}$ to -4 mcty for short series, to about 10 to $20 \mathrm{~cm} / \mathrm{cty}$ for the longest series (120 to 135 years) (Fig. 3).

Series showing a trend of $100 \mathrm{~cm} /$ cty can have a maximum length of about 50 years and for those showing trends of $\sim 100 \mathrm{~cm} / \mathrm{cty}$, a length of about 60 to 100 years.

There are series in Figure 3 with smaller lengths, however, showing the same trends ( $>0$ or $<0$ ). For trends of $220 \mathrm{~cm} / \mathrm{cty}$ the maximum series lengths are about 3 to 5 years, and similarly for trends $-220 \mathrm{~cm} / \mathrm{cty}$. These comparisons for longer series show, however, that $>0$ trended values have series lengths greater than the negatively trended ones. This is not so true for trends about $+30 \mathrm{~cm} / \mathrm{cty}$, which have series with about 35 years in length, while trends of $-30 \mathrm{~cm} / \mathrm{cty}$ have series with also similar number of years in length.

As a whole, Figure 3 seems to indicate that all trends $(C)$ have a global average mean value slightly shifted to the positive side, with a value of $10-20 \mathrm{~cm} / \mathrm{cty}$. In fact, the whole ensemble seems to be gathered in a cusped like form having in top of the figure a mean global value of $10-20 \mathrm{~cm} / \mathrm{cty}$, corresponding to the largest series of about 120 to 135 years.

There are departures from the cusped form shown by the (C) values, as those from series with lengths of 40 years to 100 years 


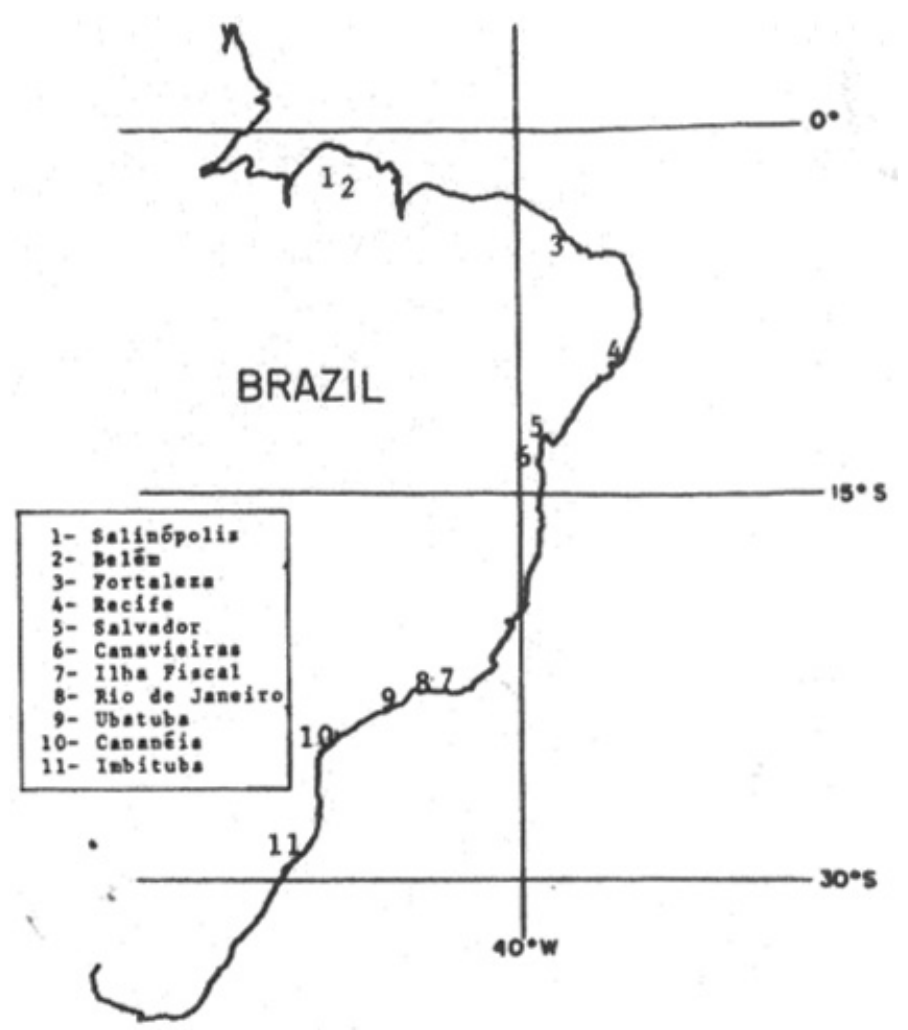

Figure 1 - Location of Brazilian ports.

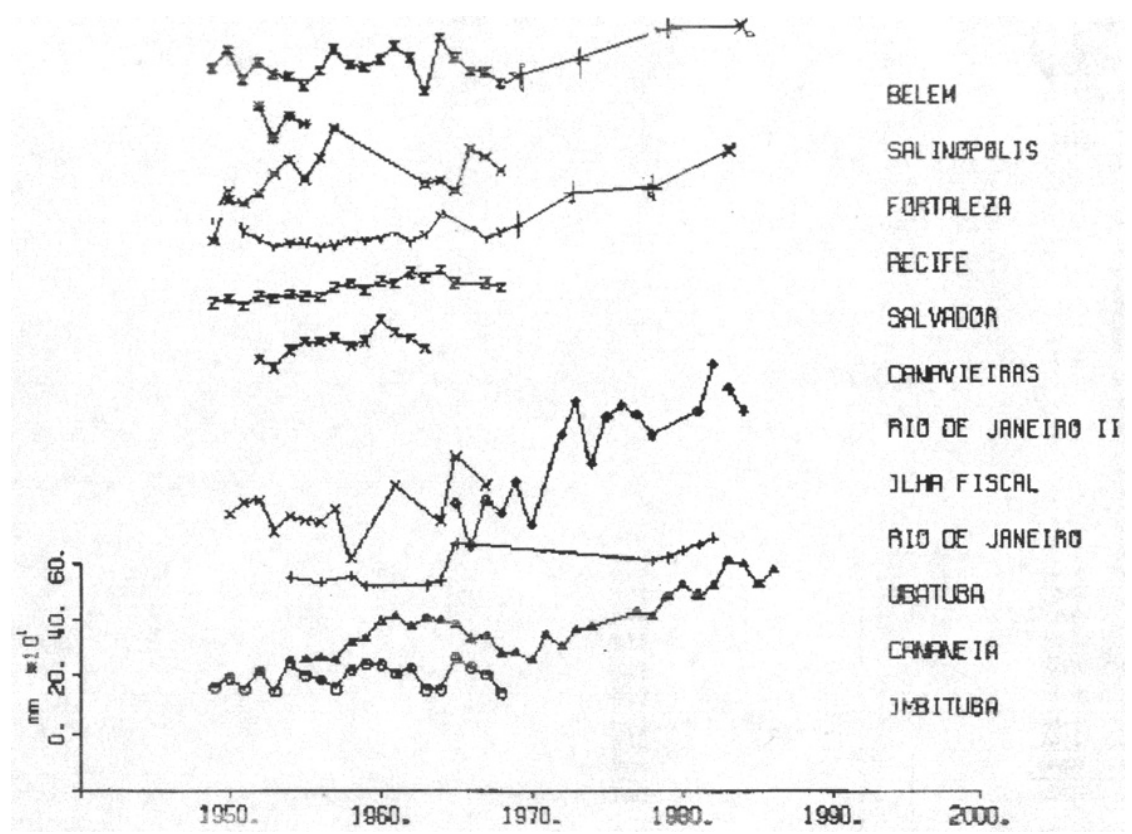

Figure 2 - Brazilian sea level data for various ports. Annual means ( $\mathrm{mm})$. The series were separated in order to have them all in the same graph. Zero of the years axis has to be displaced and put in the starting year of each series in order to estimated its trend value (Mesquita \& Harari, 2011). 


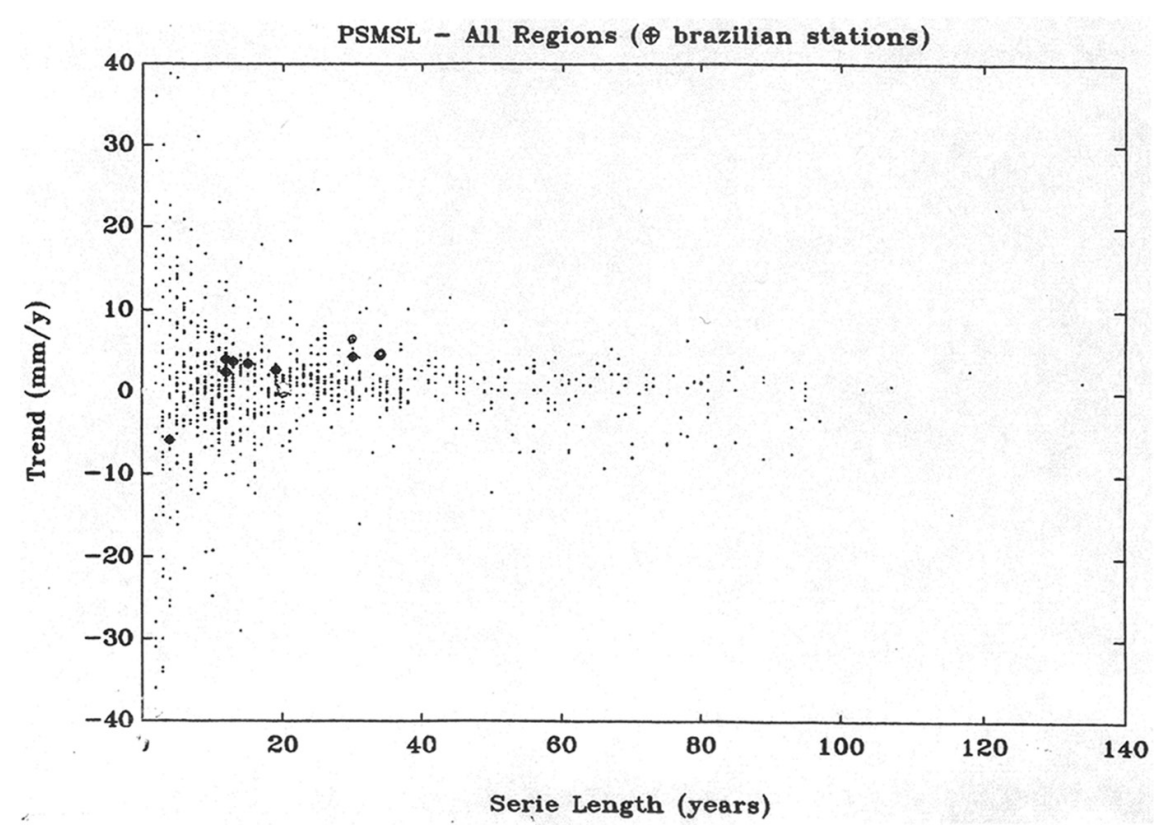

Figure 3 - A display of all trend values of PSMSL sea level series $(C)(\mathrm{mm} / \mathrm{year})$ against the length of the series in years $(\mathrm{L})$.

placed with negative trended values, which seem to be not conforming with the overall cusped distribution. They are from the ports of the Baltic Sea and seem to be following a different pattern of sea level behavior.

The great majority of $(\mathrm{C})$ values seem to depart from the main stem of the cusped, for series with lengths of less than 30 years, but there are outsiders in the negative and positive sides, which seem to spread from the common center of the cusped at larger series lengths of 50 to 80 years. The Brazilian values are well within the center of $(C)$ values, but show also outsiders from the core center, in the positive and negative sides of Figure 3. The block of series with negative trends, for series and with length of 40 to 100 years, seems not to fit the general configuration and appears to be following a different pattern of long term sea level variability.

\section{The second plot for analysis: $(\mathrm{C} \times \mathrm{m})$ plot}

In order to have a look in the positive and negative values of $(C)$ separately, Figure 4 shows a plot of the $(C)$ values of all sea level series around the world that started in 1920 against the corresponding values of $(\mathrm{m})$. These $(\mathrm{m})$ values, for the African Atlantic and South American borders, correspond to the correlation of the actual data with the data predicted by using expression $y *=a+C \cdot t$, where $a$ is a real constant, of their regression lines, whose inclinations defined the $(C)$ values. Values of $(m)$ were separated into bins $(0,-1,1-2,2-3, \ldots$ etc. $)$ from where the mean values of each bin were calculated.
Numbers on the top in Figure 4, each bin, indicate the number of values of $(\mathrm{C})$, basically the number of series, that are correspondent in each bin to the (m) values. Short series fit well their straight lines and, in general, have the highest values of $(C)$ and $(\mathrm{m})$. There are also, however, lower values of $(\mathrm{C})$ that are correspondent to higher values of $(\mathrm{m})$ and whose variability causes the greatest error bars (two std) associated to each bin.

Values of $(\mathrm{C})$ close to $\mathrm{C}=0$ correspond to the correlation coefficient $(\mathrm{m})$ close to $\mathrm{m}=0$, and there are little departures from these values, i.e., all series with $\mathrm{m}=\sim 0$ have also $\mathrm{C}=\sim 0$, which causes the small error bars of values of $(C)$ values in the bins of (m), from 0 , to +1 and from 0 to -1 . Trend values are well displayed along bins of $(\mathrm{m})$ up to $\mathrm{m}=0.5$ and are placed along two differently trended straight lines one in the positive and the other in the negative side of Figure 4.

This indicates that there must be a linear relationship between $(C)$ and $(m)$ values and that the negative trended side and the positive side of Figure 4 may vary with different rates. Values of the rates vary from $C^{*} 1=-1.1(\mathrm{~cm} /$ year) $/ 1$ (collinearity) to $C^{*} 2=+0.9(\mathrm{~cm} / \mathrm{year}) / 1$ (collinearity), with a rate of $R=$ $C^{*} 1 / C^{\star} 2=-1.2$. From what one sees that there may not be a balance between rising and sinking areas of the globe for series having bins within $m=0.5$. From these values of $(m)$, values of (C) seem to increase with $(m)$, in an apparent linear way, turning more difficult to quantify to which side the overall mean trend, $(\mathrm{C})$, is tending to. 


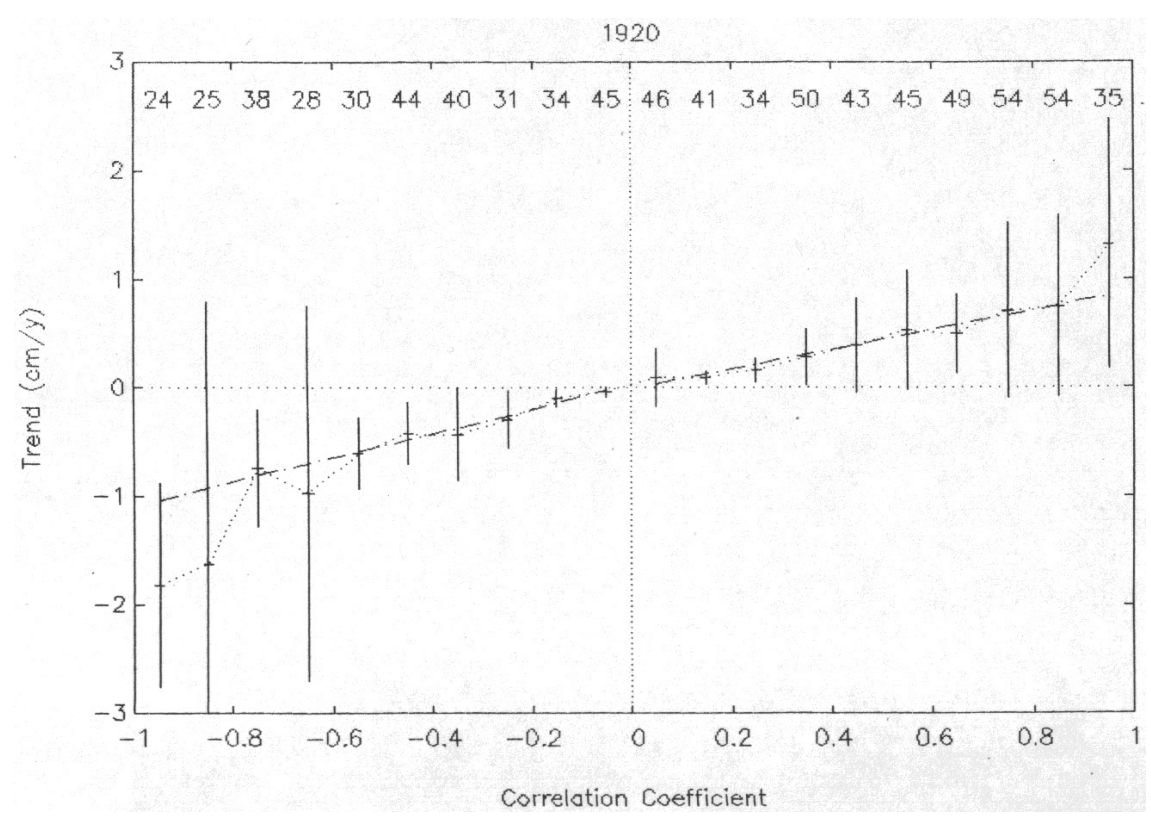

Figure 4 - Trend values (C) of PSMSL data, for series starting in year 1920, against the respective correlation (m) values. Correlation values were separated into 20 bins. Numbers on top of the figure indicate the amount of $(C)$ values in each bin. Correlation $(\mathrm{m})$ for trends $\mathrm{C}^{\star} 1<0$ were taken as negative in order to separate the bins with $\mathrm{C}^{\star} 2>0$ from bins with $\mathrm{C}^{*} 1<0$. Note the error bars of each bin's mean tending to zero value, as $\mathrm{C}$ and $\mathrm{m} 0$.

From Figure 4 one also sees that whatever are the series lengths it the vicinity of $(\mathrm{m})$ values near to zero, their trend value (C) is also correspondingly close to zero. Meaning that according to the plot, series with $m=0$ have necessarily $C=0$, whatever are their lengths $(\mathrm{L})$; consequently, their $(\mathrm{C})$ standard deviations are nearly zero at bins close to 0 . One sees from Appendix 1 that the reciprocate of this affirmative is not true, i.e., for $\mathrm{C}=0$, (m) can have any value, as they, $(\mathrm{C}$ and $\mathrm{m})$, are, independent statistical variables. In fact one sees in the Appendix 1 that for $m=0,(C)$ can also take any value. This is contrary of what is exhibited by Figure 4 , which shows a collinearity between trends $C$ and correlation values $\mathrm{m}$.

The mean values of $(C)$ in each class are representative of a set of series, whose correlation values $(\mathrm{m})$ are limited to a given interval. Each element of the bin may belong to series from any continental margin or island around the world having sea level series with that particular value for the correlation $(\mathrm{m})$.

The plot in Figure 4 splits completely the positive values from the negative values of $(C)$. The standard deviation shown by the error bars associated to each value of (C) represents the spreading of $(C)$ values supposedly Gaussian around each mean. The mean is closer to its true value, as the number of elements of each bin increases. The set of numbers on top of Figure 4 indicate an almost uniform distribution set of trends over the bins of the
Figure. The mean of each bin is an acceptable value, representing the set of values $(\mathrm{C})$ of each interval of $(\mathrm{m})$ values. The greater the number of elements of $(C)$ in each bin, the best is the mean value of $(C)$ of the bin representing the true value of the average of $m$ values.

The means of each bin represent the average values of sea level trends of series coming from different ports of the world. The means are estimates of the real values of the trends of relative mean sea level, displayed against the (m) values. They may be used then to estimate the mean global relative sea level trend $C^{*}$ by adding the $C^{*} 1$ and $C^{*} 2$ values of Figure 4 . Surprisingly all the estimates of global mean based on this procedure give $C^{*}=-130 \mathrm{~cm} / \mathrm{cty}$, by weighting each mean value of $(C)$ with the correlation value $(\mathrm{m})$ of each bin; gives $\mathrm{C}^{*}=-12 \mathrm{~cm} / \mathrm{cty}$, when weighting with the number of series in each bin and gives $\mathrm{C}^{*}=$ $-17 \mathrm{~cm} / \mathrm{cty}$, when using no weights. One should accept the last value and that means accept that the Global relative mean sea level is diminishing, which is very unexpected.

\section{Analysis of $\mathbf{C} \times \mathbf{m}$ plots of all regions}

These general inferences are also obtained from sets of series of all the continental margins from Europe Atlantic to Indian Ocean. In some cases the amount of series in each coast is not enough to fill all the bins of $(m)$ with $(C)$ values in similar plots as Figure 4. 
The South American Pacific and Atlantic, the African Atlantic the Mediterranean and Black Sea, the North American Atlantic and Pacific data have few bins with no elements. The Europe Atlantic and the Indian regions show all classes filled with at least one (C) value. In spite of that, data from all coasts exhibited positive and negative values of $(\mathrm{C})$, in such a way to fill almost all bins, as can be seen in the numbers on the top part of Figure 4.

The Indian Ocean Coasts have a small number of elements in each bin, but there are Cs distributed in all bins, so that they can define a clear tendency towards the lower values of negative $(C)$ values, corresponding to higher values of correlation ( $m$ ).

The only PSMSL series to show an almost symmetrical distribution of $(\mathrm{C})$ values, along all the bins, are those from Europe Atlantic, although the number of values of $(\mathrm{C})$ in the positive side of is much greater than in the negative one. In the overall, for the analysis of $\mathrm{C} \times \mathrm{m}$ plots of all regions one can say, that although the few bins of $(\mathrm{m})$ are not all filled in with $(\mathrm{C})$ values, the amount of data in (Fig. 4) seems to be sufficient and adequate to allow the inference that there is, in all coasts, a reasonable distribution of $(C)$ values, along the positive and negative classes of $(m)$ to reach the reasonable but unexpected inference that there is an apparent tendency, of almost all coasts, to have an imbalance towards the negative $(C)$ values in all similar graphs as Figure 4.

\section{RESULTS and DISCUSSION \\ The trends of the Brazilian coast}

An expanded plot of a set of values of $(C)$ for the Brazilian coast (Atlantic), South American Pacific and the African Coast is shown in Figure 5. The figure is similar to Figure 4, showing also the error bars and the number of series, in each bin of correlations, now indicated by circles. The trends ( $C$ values) in $\mathrm{cm} / \mathrm{cty}$ of the new set are displayed in Figure 6, as a function of the series lengths, similarly as in Figure 3 where all PSMSL set of series were represented. The lines joining the points of the figure are hypothetical, linking the $(\mathrm{C})$ values for series of all coasts, in a such way to adjust its mean value to 10 to $20 \mathrm{~cm} / \mathrm{cty}$ of the planetary series. The dashed lines indicate an area where trends $(\mathrm{C})$ values of the series have $m$ values of correlation less than 0.3 .

The overall mean, as indicated by the peak of the joining lines, was taken from Figure 3 as about 10 to $20 \mathrm{~cm} / \mathrm{cty}$ for the entire set of data. It is difficult however to give a mean value for the sea trends of the Brazilian coast, as the $(\mathrm{C})$ values are distributed oddly but an approximate mean was taken as within 20-30 cm/cty from the relative positions of the trends in the figure.

The $(\mathrm{C} \times \mathrm{m})$ plot, shown in Figure 5 , has numbers between the error bars indicating the number of $(\mathrm{C})$ values that were taken to compute the means. As in Figure 4, the standard deviations are smaller for $(C)$ values between $30 \mathrm{~cm} / \mathrm{cty}$ or $\mathrm{m}=0.3$, and the positive and negative sides of the inclination of lines of $(C)$ values, then created, are not compensating each other. From that point the curve increases in an almost exponential way, as indicated by the dashed line made purposely symmetrical for comparison with the actual curve which seems to be very asymmetrical.

The estimate the global relative mean sea level from (C) values, in Figure 5, taken along the exponential line, would result in a nil value. As can be seen, there are pronounced dissimilarities between the positive and negative values of the new trends $C^{*} 1<0 \approx-120 / 1$ collinearity and $C^{*} 2>0 \approx+40 \mathrm{~cm} / \mathrm{cty} / 1$ collinearity with a mean $\mathrm{C}^{\star} \approx-65 \mathrm{~cm} / \mathrm{cty}$ in Figure 5 .

In Figure 6 crosses indicate the Brazilian data; they are mostly above the limit of $m=0.3$ shown by the dashed area. The trend values of Salinópolis, Pará State and Angra dos Reis, Rio de Janeiro State, with only 4 years of data, are definitely on the negative and positive side of the plot. In the positive side are the ports of Canavieiras, with fifteen years of data, and the port of Ilha Grande, with six years of data. Most of the series (Recife, Salvador... etc.) have less than 30 years of data and are in the central part of the cusped distribution of C's, producing by visual of the graph, an estimation of $\mathrm{C}$, a value within $20-30 \mathrm{~cm} / \mathrm{cty}$, which was accepted as more representative of the geographical area.

Sea Level data as taken in the present analysis, represent the ocean response to several factors, such as changes in global air temperature, causing the greenhouse effect, global expansion of sea volume as a consequence of the thermal increase of sea water volume and due to the melting of low latitude glaciers, vertical movement, sinking and uplifting of land, where the tide gauges are situated, long term variation of atmospheric pressure fields, precipitation, air temperature, changes in oceanic circulation patterns, and others.

The expectation in this work was that, by analyzing the data globally, one will have the overall picture of the distribution of data, allowing to infer the general trends where the Brazilian sea level data fit in.

The expectative were that global sea levels have increased since last century, by approximately $10-20 \mathrm{~cm}$ (Gornitz et al., 1982), due to the melting of the polar ice caps and the thermal expansion of the sea water. Trends of all records, are contaminated by vertical movements of the land, where the gauges are fixed in. In some works like Barnett (1983) the land motions are expected to be reduced, by averaging the records from many stations; in others, the land movements are estimated from geological evidence (Gornitz et al., 1982). 


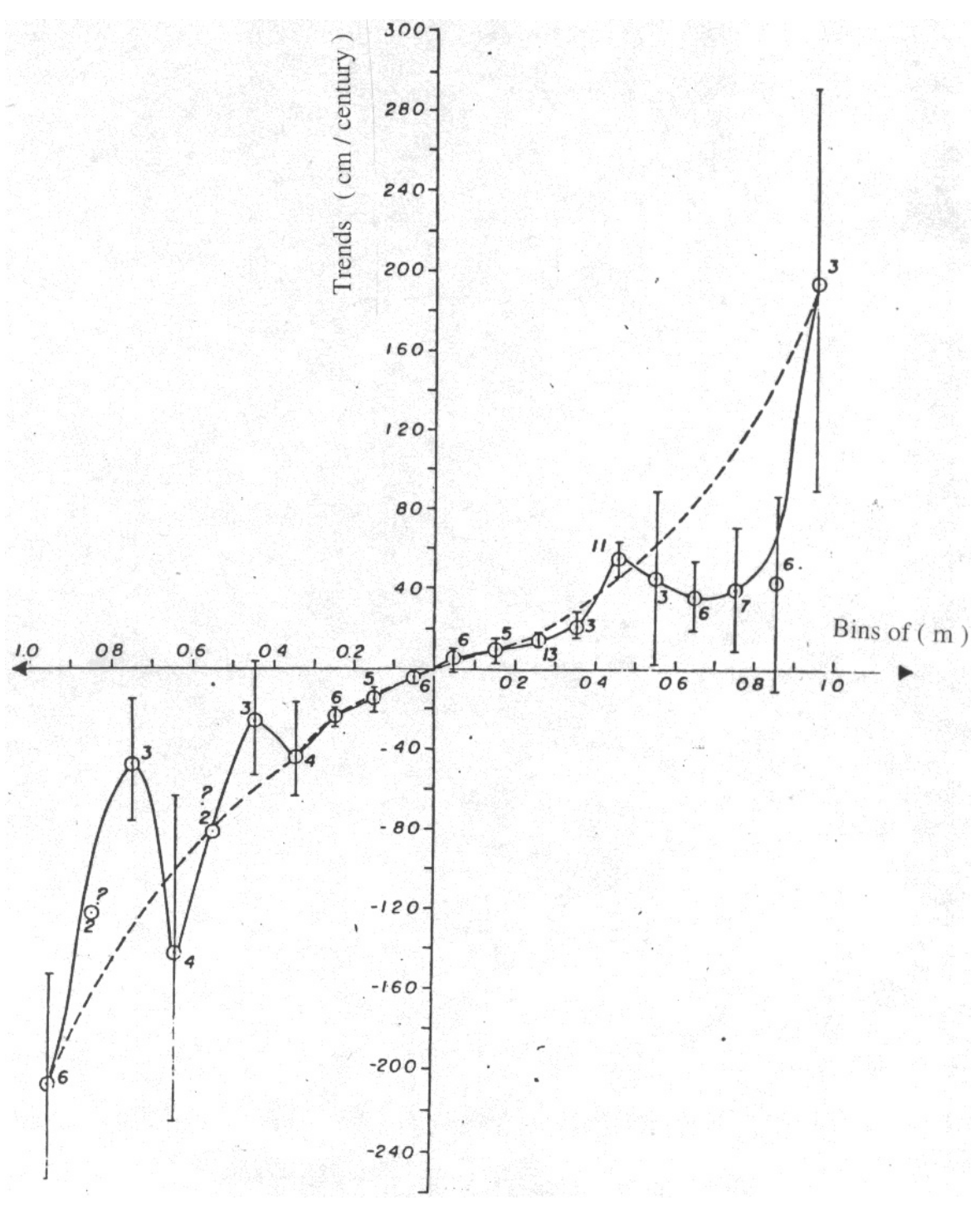

Figure 5 - An expanded plot of $(C \times m)$ values for the South American ports. Circles indicate trend $(C)$ values of each correlation bin $(\mathrm{m})$. Number of data used for calculating the mean trend of the bin is shown near the center of the error bars. Note the values of the error bars diminish to the value trend equal zero Dashed line indicates a nearly parabolic symmetrical line along which there would be an overall balance between positive and negative (C) values (Mesquita \& Leite, 1986).

Therefore when long term data set are assembled from tide gauges, it is misleading to take the global average as eustatic because of the bias of most islands and continental margins towards submergence (Woodworth, 1990).

Brazilian sea level trends shown in Figures 3 and 6 seem to be responding to many of these aspects. In ther central parts are the trends of ports which belong to the east coast, such as Salvador, Recife, Canavieiras and Rio Janeiro. The largest positive value of $(C)$ is found in Cananeia, the longest series of Brazilian ports available for this analysis. It seems that as the series be- come longer, values of $(\mathrm{C})$ will follow the lines to the central value of $\sim 10 \mathrm{~cm} / \mathrm{cty}$, previously accepted as the average value of $(\mathrm{C})$ before drawing Figure 6. That aspect was established in Figure 3, where all the $(\mathrm{C})$ values from PSMSL series were plotted without making any assumption; it also repeats the Global estimate of (C) of Gornitz et al. (1982), with 10-20 cm/cty for the longest series of 122 and 135 years.

The main feature of Figures 3 and 6 is the display of negative and positive values of $(\mathrm{C})$, which spread almost symmetrically around a mean central value, taken as the Global relative mean 
sea level trend. To the largest positive (C) Figure 6 the value of $180 \mathrm{~cm} / \mathrm{cty}$ correspond negative (C) values of $-200 \mathrm{~cm} / \mathrm{cty}$, for series having less than 10 years of length. This seems to be also the case for low values of $\mathrm{C}=+20 \mathrm{~cm} / \mathrm{cty}$, which can be put in correspondence to negative values of $\mathrm{C}=-20 \mathrm{~cm} / \mathrm{cty}$, again almost symmetrically distributed relative a central value (see actual Fig. 5 and Fig. 4) close but not quite to $C=0$.

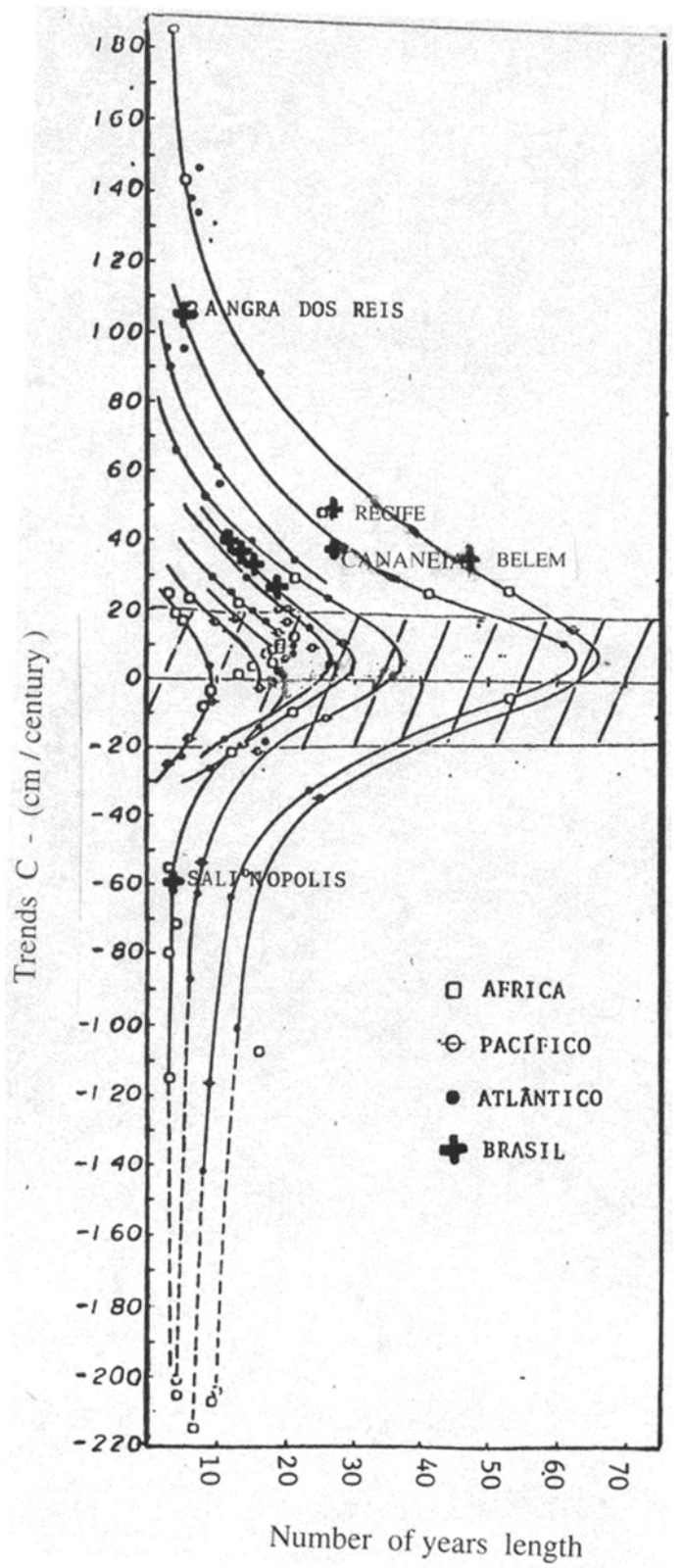

Figure 6 - Values of (C) for African, Pacific, Atlantic and Brazilian ports against the lengths of the series. Lines drawn are hypothetical to display a symmetry between positive and negative $C$ taking the $10 \mathrm{~cm} / \mathrm{cty}$ long term mean as realistic value for the mean. Dashed area indicates series with correlation values in the interval $-0.3<m<+0.3$. Based on Mesquita \& Leite, 1986.
The lines of Figure 6 were drawn to emphasize that feature and no physical meaning can be attached to them, so far. It may be a matter of further measurement and research to follow the evolution of the Brazilian trends indicated in Figure 6, as they increase in number of measurements, i.e., in number of years.

All of the Brazilian data are out of the limits of $m=0.3$, where, in the figure, the standard deviations of the means of the bins are the smallest calculated. As the lengths of the series are less than 20 years, trends are generally higher than $30 \mathrm{~cm} / \mathrm{cty}$. Several causes can be producing the present short terms changes as such one.

As the Brazilian series in this analysis fall in the range 2030 years, their trends may be influenced by actions originated in the atmospheric pressure variations in the Southern hemisphere. Mesquita et al. (1986) noted an increase of pressure gradients along the Southern and Northern parts of the coast, which may be associated to displacements of the high atmospheric pressure zone in the South Atlantic, from its position close to South Africa, to a position closer to South America causing the decrease of the long term sea level.

Positive or negative trends of sea surface, along the entire coast, can be also associated to atmospheric precipitation. On the spectral bands of 2-3 years 5-7 years and 26 years of precipitation found by (Morettin et al., 1985) may also be relevant contribution to that variability of the sea level, not only in the Brazilian coast, but in all sea level series of PSMSL. Similar time scales have been reported by Sturges (1987) as associated to propagating Rossby waves in the Pacific with periods of 40 to 50 years and 5-15 cm amplitude, between the coast of Europe and the United States.

Present estimates can reflect also the effects of sea level warming due to the $\mathrm{CO} 2$ and other gases, as they are calculated from relatively recent parts of the series (less than 35 years), and they may be undergoing similar acceleration rates found by Woodworth (1990), in long records of Europe, who foresees global sea level of acceleration rates of $0.4 \mathrm{~mm} / \mathrm{year} / \mathrm{cty}$ by the early years of the this XXI century.

The overall results from Figure 3 to 6 and the values given by Barnet (1983) and by Gornitz et al. (1982), (20-30 cm/cty), tend to indicate a different global value for the trend of r.s.l as given by Figures 4 and $5,(-17 \mathrm{~cm} / \mathrm{cty}$ and $-65 \mathrm{~cm} / \mathrm{cty})$. This seems to be due that these authors did not take all the RLRANN data distributed by the PSMSL, but worked on a very select number of series, which made the values of Figure 3 for long series, to be positive and similar to those of these authors. 
The present approach, by taking into classes series with same $(C)$ and $(m)$ characteristics, allows that a greater number of values from series of ports all over the world to be averaged in a same bin, which tends to eliminate their shorter term oceanographical, geophysical and meteorological biases in the averaging and incorporated all the negative trends in the global mean trend, which could not be taken in their approach. Therefore the present methods seem to be more adequate to reaching the more accurate global mean value for the global relative sea level.

For that it was fortuitous to find the mean trends of the bins in Figures 4 and 5 were displayed along two differently trended straight lines in the positive and negative sides of the graph, which facilitated the calculation and probably unveiled a new property of the planet not detected by other analyses. The fact that the Global mean trend of relative sea level to be negative has been pointed out also by Barnett (1983) and present results might be going in the same direction.

Some studies try to explicitly estimate land movements from models (Peltier et al., 1978) or from geological evidence from Holocene fluctuations, in order to estimate global and regional eustatic sea level series (Gornitz et al., 1982). In fact, most of the short series seem to vary also in response to sinking and uplifting of the sites where the tide gauges are. These characteristics tend to form, with the long term geological causes, important causes for sea level variability, making the extraction of a climatological component difficult, in series where the vertical land movements are clear and its determination can be not easy. The identification appears to be only possible with new technology, (Woodworth, 1990) by the use of Satellite Laser Ranging (SLR), combined with Global Positioning System (GPS), very long base line interferometry and absolute gravity measurements. They will help to measure independently the land movements, in a geocentric reference frame and identify them in tide gauge records.

Negative overall trends of relative sea level have been pointed out in earlier determinations of mean Global relative sea level trends (Barnett, 1983) and may become common as a greater number of sea level, geophysical and meteorological measurements from the Artic and the Antarctic, as well as, the Tropics and other active areas of the crust, are taken into consideration.

However in spite of the above uncertainties one can assure that the most probable rate of variation of relative sea level of the Brazilian coast, estimated in Figures 3 and 6 as around 20 to $30 \mathrm{~cm} / \mathrm{cty}$, is to this time, the best estimative.

\section{CONCLUSIONS}

Brazilian trends $(\mathrm{C})$, in a plot of all PSMSL data versus length of the series $(\mathrm{L})$, are mostly concentrated in the positive side of
Figures 3 and 6. Ports of Belém, Fortaleza, Recife, Canavieiras, Salvador, Iha Fiscal, Rio de Janeiro, Ubatuba, Cananeia and Imbituba have positive trends with a mean value within $30-40 \mathrm{~cm} / \mathrm{cty}$.

The analysis of series with different lengths from South American and Atlantic Ocean African coast (Fig. 6), produced a plot (Fig. 5), of bins of ( $\mathrm{m}$ ) against the trends (C), which showed that values (C) within $\pm 30 \mathrm{~cm} / \mathrm{cty}$, have correspondingly values of correlation lesser than $m=0.3$ whatever their lengths $(L)$ in years.

The $(\mathrm{C} \times \mathrm{m})$ plots (Figs. 4 and 5$)$ showed straight lines in the positive and negative sides of the graph with different inclinations, $C^{*}<0$ and $C^{*} 2>0$ seeming to indicate, that they are, in a global mean, dependent variables. Also contrary to what was expected, the sum of the two new trends $C^{\star}$ of the plot Figure 4 , has a global negative value, which is opposite to the value estimated (10 to $20 \mathrm{~cm} / \mathrm{cty}$ ) in the present study for the global mean sea level increase.

Similar analyses for the South Atlantic and African sea level (Fig. 5) have also an overall balance towards the negative side of the plot. In spite these interesting but contradictory results, that are not fully understood and deserve more analyses, there seems to be no doubts, however, from the present analysis that the relative sea level along the Brazilian coast is increasing at rates of 30 to $40 \mathrm{~cm} / \mathrm{cty}$.

\section{ACKNOWLEDGMENTS}

We are thankful to Dr. Philip Woodworth from the PSMSL for several useful suggestions, as well as, by sending the PSMSL data. Dr. Ricardo Camargo did the programming and prepared the computer plots.

\section{REFERENCES}

BARNETT TP. 1983. Recent changes in sea level and their possible causes. Climatic Changes, 5: 15-38.

GORNITZ V, LEBEDEFF S \& HANSEN J. 1982. Global sea level trend in the past century. Science, 215: 1611-1614.

MESQUITA AR de \& LEITE JB de A. 1986. Sobre a Variabilidade do Nível do Mar na Costa Sudeste do Brasil. Revista Brasileira de Geofísica, 4(2): 229-236.

MESQUITA AR de \& HARARI J. 2011. Early and Recent Sea Level Measurements in the Brazilian Coast. Afro-America Gloss News Edição, 15(1). Available on: www.mares.io.usp.br. Access on: Jan.03.2012.

MESQUITA AR de, FRANCO A dos S \& HARARI J. 1986. On mean sea level along the Brazilian coast. Part I. Geophys. J.R. Astr. Soc., 87: $67-77$. 
MORETTIN PA, MESQUITA AR de \& ROCHA JGC. 1985. Rainfall at Fortaleza-Brazil Revisited. In: ANDERSON OD, ORD JK \& ROBINSON EA (Eds.). Time Series Analysis Theory and Practice 6. Horth Holland, $67-85$.

PELTIER WR, FARREL WE \& CLARK JA. 1978. Glacial isostasy and relative sea level: a global finite element model. Tectonophysics, 50: 81110.

SELBY S. 1969. Standard Mathematical Tables 17th Edition. The Chemical Rubber Co, 18901, Cranwood, Parkway, Cleveland, Ohio 44128, 720 pp.

STURGES W. 1987. Large-scale coherence of sea level at very low frequencies. J. Phys. Oceanogr., 17: 2084-2094.

WO0DWORTH PL. 1990. A search for accelerations in records of European mean sea level. International Journal of Climatology, 10: 129-149.

\section{APPENDIX 1}

\section{The Trend $\times$ Correlation Plot $-(\mathrm{C} \times \mathrm{m})$ Plot}

The trend value $(C)$ of each sea level time series, that were used in the $(\mathrm{C} \times \mathrm{m})$ plot, was calculated by using expressions taken from Standard Mathematical Tables (Selby 1969).

$$
C=\frac{N \sum x_{i} y_{i}-\left(\sum x_{i}\right)\left(\sum y_{i}\right)}{N \sum x_{i}^{2}-\left(\sum x_{i}\right)^{2}}, \quad i=1,2, \ldots, N
$$

where $x_{i}$ are the sea level heights of the sea level series and $y_{i}$ are their corresponding values of instants $t_{i}$ of a series with $N$ pairs $\left(x_{i}, y_{i}\right)$.

The correlation $(m)$ of the $N$ pairs $\left(x_{i}, t_{i}\right)$, was calculated, once the $(C)$ values were known from (1) by using the expression below:

$$
\begin{gathered}
m=\frac{\frac{1}{N} \sum C \cdot\left(x_{i}-\bar{x}\right)\left(t_{i}-\bar{t}\right)}{\sqrt{\sum \frac{C^{2} \cdot\left(x_{i}-\bar{x}\right)^{2}}{N} \cdot \sum \frac{\left(t_{i}-\bar{t}\right)^{2}}{N}}}, \text { where } \\
\bar{t}=\frac{\sum t_{i}}{N} \text { and } \bar{x}=\frac{\sum x_{i}}{N}, \text { for } i=1,2, \ldots, N
\end{gathered}
$$

It follows, by putting in evidence $(C / N), N \neq 0$ and canceling them in denominator and numerator that:

$$
m=\frac{\sum\left(x_{i}-\bar{x}\right)\left(t_{i}-\bar{t}\right)}{\sqrt{\sum\left(x_{i}-\bar{x}\right)^{2} \sum\left(t_{i}-\bar{t}\right)^{2}}}, \quad i=1,2,3, \ldots, N
$$

From which one can see that for each sea level series, the trend value $(C)$ does not appear in expression (3) which was used to determine the correlation $(m)$. Therefore the $(m)$ value does not depend of its corresponding $(C)$ value. Similarly the $(C)$ value does not depend on the $(m)$ value, as the $(m)$ value does not appear in expression (1) used to calculate $(C)$. The trend values $(C)$ and the correlation coefficients $(\mathrm{m})$ are then mutually independent statistical variables.

\section{NOTES ABOUT THE AUTHORS}

Afrânio Rubens de Mesquita is a Physicist graduated from the Instituto de Física of the Universidade de São Paulo. Professor at the Instituto Oceanográfico of the Universidade de São Paulo and member of the Science History Center of the Universidade de São Paulo, PSMSL (Permanent Service for the Mean Sea Level) of IAPSO (International Association for the Physical Sciences of the Oceans), and MenGroup of Experts of GLOSS (Global Observing Sea Level System) of IOC (Intergovernmental Oceanographic Committee) of UNESCO.

Alberto dos Santos Franco is na Admiral (Reserve) of the Brazilian Navy. Doctor from the escola Politécinica de São Paulo and Emeritus professor of the Instituto Oceanográfico of the Universidade de São Paulo. Is the author of several books on Analysis of Tides. Was director of the International Hydrographic Bureau of Monaco, Europe.

Joseph Harari is a Physicist from the Instituto de Física of the Universidade de São Paulo and associate Professor in the Department of Physical Oceanography of the Instituto Oceanográfico of the Universidade de São Paulo, where specializes in the numerical solution of the hydrodynamic equations and analysis of tides.

Carlos Augusto de Sampaio França is a Physicist from the Instituto de Física da Universidade de São Paulo and a PhD in Physical Oceanography in the Instituto Oceanográfico of the Universidade de São Paulo, where works as a Physicist. Specializes in the treatment and analysis of altimetric sea measurements and the solution of the hydrodynamic equations in the Equatorial and South Atlantic. 